\title{
A RELEVÂNCIA DA PUBLICAÇÃO CIENTÍFICA PARA A INOVAÇÃO C\&T
}

\author{
The Relevance of Scientific Publishing for Innovation in Science and Technology
}

\author{
Edson Marchiori ${ }^{1}$
}

A atividade médica diária, mesmo em meios acadêmicos, é em geral tão intensa e absorvente, que pouco tempo deixa para os profissionais desenvolverem pesquisa, e especialmente divulgar os resultados através de publicações em revistas indexadas. De uma forma geral, esta atividade é vista como secundária, periférica, para ser desenvolvida "fora do horário de trabalho". Esta, infelizmente, ainda é a visão de muitos dirigentes acadêmicos, que não percebem a importância da pesquisa para o desenvolvimento científico e tecnológico da nação.

Apesar de todas as dificuldades, a produção científica brasileira vem crescendo progressivamente. Em 1998, ocupávamos a $22^{\text {a }}$ posição mundial. Uma década depois, saltamos para a 13a posição. Vários fatores influíram nesta arrancada, mas certamente a contribuição das políticas de incentivo desenvolvidas especialmente pela Coordenação de Aperfeiçoamento de Pessoal de Nível Superior (Capes) e pelo Conselho Nacional de Desenvolvimento Científico e Tecnológico (CNPq), foi decisiva para este crescimento.

Segundo Guimarães', o aporte de recursos de fomento das agências federais; a adesão de muitos estados, que passaram a financiar substancialmente as atividades de pesquisa (FAPESP, FAPERJ, etc); o crescimento do número das bolsas federais; o crescimento de titulados na pós-graduação, sobretudo no doutorado, onde se dá a maior parte da produção científica brasileira; a cobrança de melhor desempenho individual dos pesquisadores na avaliação pelas agências de fomento; as exigências de desempenho dos cursos nas avaliações da pós-graduação pela Capes; e o papel do Portal de Periódicos da Capes, que possibilita o acesso à parte importante da literatura científica mundial, formam um conjunto de elementos que foram fundamentais para estes expressivos resultados. A qualidade e o crescimento da pós-graduação brasileira são, sem dúvida alguma, os principais fatores responsáveis por este avanço.

A produção científica de um país torna-se visível pela publicação de artigos originais em revistas internacionais indexadas. Entre as diversas bases de dados capazes de fazer essa indexação, destacam-se duas no âmbito internacional: Institute for Scientific Information (ISI) e Base Scopus. A criação de novas revistas, o esforço dos editores em busca da sua melhor qualificação e conseqüente indexação, é mais um fator que vem se juntar aos já relatados nesta rota de crescimento. Ainda segundo Guimarães', é esta a trajetória do Brasil, que felizmente aos poucos está descobrindo que sem educação, ciência e tecnologia não se pode pretender ser um país economicamente desenvolvido e socialmente justo.

\footnotetext{
1. Professor Associado de Radiologia da Universidade Federal do Rio de Janeiro. Endereço Eletrônico: edmarchiori@gmail.com (Edson Marchiori).

Referência

1. Guimarães JA. As razões para o avanço da produção científica brasileira. Disponível em http://www.capes.gov.br/servicos/sala-de-imprensa/artigos/4720-as-razoes-para-oavanco-da-producao-cientifica-brasileira. [acesso em: 28/09/2012].
} 